\title{
A cross sectional questionnaire based study on self medication practice of analgesics among MBBS students at Dr. B. R. Ambedkar Medical College, Bengaluru, Karnataka
}

\author{
Shanmukananda P., Shwetha H.*, Veena D. R., Poorvi M.
}

Department of Pharmacology, Dr. B. R. Ambedkar Medical College, Bengaluru, Karnataka, India

Received: 29 January 2020

Accepted: 07 March 2020

\section{*Correspondence:}

Dr. Shwetha H.,

Email: shwetha.bhavani@gmail.com

Copyright: (c) the author(s), publisher and licensee Medip Academy. This is an open-access article distributed under the terms of the Creative Commons Attribution Non-Commercial License, which permits unrestricted non-commercial use, distribution, and reproduction in any medium, provided the original work is properly cited.

\begin{abstract}
Background: Self medication with analgesics is prevalent worldwide due to easy procurement of over the counter drugs. Present study was done to assess knowledge, attitude, practice and perception of self medication of analgesics among MBBS students at Dr. B. R. Ambedkar Medical College, Bengaluru, Karnataka.

Methods: A cross-sectional study was conducted on $5^{\text {th }}$ term MBBS students of Dr. B. R. Ambedkar Medical College, Bengaluru in November 2019. A pre-designed validated questionnaire was used to collect information on knowledge, attitude, practice and perception of self medication of analgesics. Data was analysed using descriptive statistics.

Results: $83.3 \%$ of $5^{\text {th }}$ term MBBS students practiced self medication with analgesics. Majority of students had some knowledge on self medication with analgesics. Common reason for using analgesic self medication was headache (59.7\%) and nonsteroidal antiinflammatory drugs (90\%) were commonly used analgesics. Analgesics were used for quick relief $(73.3 \%)$ and source of information was from medical textbooks $(61.6 \%)$. Students stopped taking analgesics after symptoms disappeared (75\%). Students agreed that self medication is acceptable for medical students $(63.3 \%)$ and medical license is required for better administration of drugs $(51.3 \%)$.

Conclusions: This study has found that self medication with analgesics was common among undergraduate medical students for minor illness. It is necessary to create awareness and educate students regarding dangers of analgesic self medication.
\end{abstract}

Keywords: Analgesics, Internet, Medical students, Medical textbooks, Self medication

\section{INTRODUCTION}

According to the WHO's definition "self medication is the use of drugs to treat self-diagnosed disorders or symptoms, or the intermittent or continued use of a prescribe drug for chronic or recurrent diseases or symptoms."1 In studies conducted within India, the prevalence of self-medication among the undergraduate medical students was shown to be ranging between $57.1 \%$ and $92 \% .^{2-4}$ Academic level is an important predictor of practicing self-medicationas shown in the study conducted by Klemenc-Ketis et al which stated that senior health science students were found to be morelikely consumers of analgesics, compared to junior students. ${ }^{5}$ Having adequate knowledge about medications is also a possible risk factor for self-medication among health sciences students. ${ }^{6}$

Pain is an important symptom for self medication with analgesics. Analgesic self-medication is widely prevalent among undergraduate medical students. A study conducted at the All India Institute of Medical Sciences, 
New Delhi observed that self-medication was considerably high among under-graduate medical and paramedical students in India and it increased with medical knowledge. ${ }^{7}$

Being future medical practitioners, self medication has a special impact on medical students.

This raises concerns of incorrect self-diagnosis, drug interactions, and use of drugs other than for the original indication. Hence, the present study was conducted to assess the knowledge, attitude, practice and perception of self medication of analgesics among MBBS students at Dr. B. R. Ambedkar Medical College, Bengaluru.

\section{METHODS}

This was a cross-sectional study conducted on $5^{\text {th }}$ term MBBS students of Dr. B. R. Ambedkar Medical College, Bengaluru in the month of november 2019. The study protocol was approved by the Institutional Ethics Committee, of Dr. B. R. Ambedkar Medical College, Bengaluru. Students not willing to participate in the study were excluded from the study.

A pre-designed semi-structured validated questionnaire was used to collect the relevant information, like age, gender, year of study of MBBS, and knowledge, attitude, practice and perception of self medication of analgesics. The questionnaire was a newly designed one, based on similar studies conducted previously, inputs from the faculty and validated by senior faculty.

The questionnaire was distributed to $5^{\text {th }}$ term MBBS students of Dr. B. R. Ambedkar Medical College, Bengaluru. The students were briefed on the objectives of the study. They were also informed that the information collected would be kept confidential and participation would be totally voluntary. Only completely filled questionnaire were included for statistical analysis and incompletely filled questionnaire were excluded for the analysis.

\section{Statistical analysis}

Data collected was analysed using descriptive statistics and results were expressed in numbers and percentage

\section{RESULTS}

Among 110 students belonging to $5^{\text {th }}$ term MBBS, 72 students participated in the study and filled the questionnaire. All 72 students completely filled the questionnaire.

$37(51.3 \%)$ were female and $35(48.6 \%)$ were male students. They were in the age group of 19-20 years.

Majority of the students had some knowledge regarding self medication with analgesics as shown in Table 1.

\section{Assessment of self medication practices of analgesics}

$83.3 \%$ of $5^{\text {th }}$ term MBBS students practiced self medication with analgesics. Students used self medication for headache $(59.7 \%)$, muscle pain $(56.9 \%)$, joint pain $(27.7 \%)$, dysmenorrhea (18\%), sinusitis (11.1\%) and fever (9.7\%). Commonly used analgesics were nonsteroidal antiinflammatory drugs (NSAIDs) (90\%), opioid analgesics (10\%) and combination of opioid and non-opioid analgesics $(5 \%)$. Frequency of self medication with analgesics was on as needed basis $(86.6 \%)$, monthly $(8.3 \%)$ and weekly $(5 \%)$.

Common reasons for using self medication with analgesics was for quick relief $(73.3 \%)$, it was convenient (43.3\%), had prior experience of illness (38.3\%), self confidence regarding awareness of medication (38.3\%), practiced self medication in past year (21.6\%), pharmacists advise (20\%), illness too trivial for consultation $(16.6 \%)$, first method to treat all problems and cost saving $(11.6 \%)$ and reluctance to spend money on doctor consultation and lab investigations (5\%).

Table 1: Assessment of knowledge on self medication of analgesics.

\begin{tabular}{|c|c|c|c|}
\hline Knowledge regarding self medication of analgesics & $\begin{array}{l}\mathbf{1} \\
\mathbf{N}(\%)\end{array}$ & $\begin{array}{l}\mathbf{2} \\
\mathbf{N}(\%)\end{array}$ & $\begin{array}{l}\mathbf{3} \\
\mathbf{N}(\%)\end{array}$ \\
\hline Do you have the knowledge about definition of self medication? & $2(2.7)$ & $63(87.5)$ & $7(9.7)$ \\
\hline $\begin{array}{l}\text { Do you know the difference between opioid and nonopioid } \\
\text { analgesic? }\end{array}$ & $2(2.7)$ & $65(90.2)$ & $5(6.9)$ \\
\hline $\begin{array}{l}\text { Do you know the dose of analgesic used in the treatment of the } \\
\text { concerned disease? }\end{array}$ & $4(5.5)$ & $65(90.2)$ & $3(4.1)$ \\
\hline $\begin{array}{l}\text { Do you know the duration of treatment with analgesic for the } \\
\text { concerned disease? }\end{array}$ & $5(6.9)$ & $66(91.6)$ & $1(1.3)$ \\
\hline Do you know the available dosage form of the analgesics? & $2(2.7)$ & $68(94.4)$ & $2(2.7)$ \\
\hline Do you know the timing of administration of analgesics? & $6(8.3)$ & $64(88.8)$ & $2(2.7)$ \\
\hline Do you know the side effects of analgesics? & $4(5.5)$ & $65(90.2)$ & $3(4.1)$ \\
\hline Do you know the drug interactions with the use of analgesics? & $2(2.7)$ & $68(94.4)$ & $2(2.7)$ \\
\hline Do you have knowledge about banned analgesics? & $27(37.5)$ & $42(58.3)$ & $3(4.1)$ \\
\hline
\end{tabular}

1- not at all , 2- some, 3-very much 
Source of information for self medication with analgesics was medical textbooks (61.6\%) followed by previous doctor prescriptions $(40 \%)$, opinion of family members $(35 \%)$, my own experience $(23.3 \%)$, pharmacists advise $(13.3 \%)$, opinion of friends $(11.6 \%)$ and also few of them got information from advertisement (6.6\%) and recommended by internet $(5 \%)$

Selection of analgesics was based on indication (56.6\%), type of analgesics (50\%), side effects (41.6\%), brand $(40 \%)$ and price $(10 \%)$. Students obtained analgesics from community pharmacy (80\%), e-pharmacies $(13.3 \%)$ and from left over from previous prescriptions (6.6\%). $73.3 \%$ of them checked the package insert and among them $68 \%$ of students had partly understood the instructions given in the package insert.

$60 \%$ of the students were satisfied with the use of analgesics and $30 \%$ of them experienced side effects. Students normally stopped taking self medication with analgesics after symptoms disappeared $(75 \%)$ while $10 \%$ of them stopped analgesics after consulting a doctor/pharmacist. $43.3 \%$ of the participants were not sure that they could successfully treat themselves with analgesics while $26.6 \%$ of them responded as yes and $30 \%$ of them as no. $63.3 \%$ of the participants thought that self medication with analgesics for self care is an acceptable practice and $30 \%$ of them responded that it was an unacceptable practice while only $6.6 \%$ of them said it was a good practice.

\section{Assessment of attitude on self medication of analgesics}

Majority of students agreed that self medication is acceptable for medical students $(34.7 \%)$ and it is a part of self care $(44.4 \%)$. Students strongly agreed that Medical license is required for better administration of drugs $(51.3 \%)$ as shown in Table 2.

\section{Perception of students to prevent self medication practice}

Students strongly agreed to prevent dispensing of medicine without a valid prescription $(45.8 \%)$ and also to create awareness regarding side effects of self medication $(56.9 \%)$ as shown in Table 3.

Table 2: Assessment of attitude on self medication of analgesics.

\begin{tabular}{|c|c|c|c|c|c|}
\hline $\begin{array}{l}\text { Attitude regarding self medication of } \\
\text { analgesics }\end{array}$ & $\mathbf{1}$ & $\begin{array}{l}2 \\
\mathbf{N}(\%)\end{array}$ & $\begin{array}{l}\mathbf{3} \\
\mathbf{N}(\%)\end{array}$ & $\begin{array}{l}\mathbf{N} \\
\mathbf{N}(\%)\end{array}$ & $\begin{array}{l}\mathbf{5} \\
\mathbf{N}(\%)\end{array}$ \\
\hline $\begin{array}{l}\text { Self medication is acceptable for medical } \\
\text { students }\end{array}$ & $8(11.1)$ & $25(34.7)$ & $22(30.5)$ & $12(16.6)$ & $5(6.9)$ \\
\hline $\begin{array}{l}\text { Medical students have good ability to diagnose } \\
\text { the symptoms }\end{array}$ & $4(5.5)$ & $26(36.1)$ & $22(30.5)$ & $16(22.2)$ & $4(5.5)$ \\
\hline $\begin{array}{l}\text { Medical students have good ability to treat the } \\
\text { symptoms }\end{array}$ & $1(1.3)$ & $33(45.8)$ & $15(20.8)$ & $22(30.5)$ & $1(1.3)$ \\
\hline $\begin{array}{l}\text { Self medication would be harmful if it is taken } \\
\text { without proper knowledge of drugs and disease }\end{array}$ & $35(48.6)$ & $27(37.5)$ & $4(5.5)$ & $1(1.3)$ & $5(6.9)$ \\
\hline $\begin{array}{l}\text { Medical license is required for better } \\
\text { administration of drugs }\end{array}$ & $37(51.3)$ & $20(27.7)$ & $6(8.3)$ & $5(6.9)$ & $4(5.5)$ \\
\hline $\begin{array}{l}\text { Pharmacist is a good source of information } \\
\text { regarding treatment of minor ailments }\end{array}$ & $4(5.5)$ & $27(37.5)$ & $14(19.4)$ & $16(22.2)$ & $11(15.2)$ \\
\hline Should be careful with over the counter drugs & $39(54.1)$ & $22(30.5)$ & $9(12.5)$ & $2(2.7)$ & $0(0)$ \\
\hline $\begin{array}{l}\text { Medical students should read the package } \\
\text { insert }\end{array}$ & $30(41.6)$ & $35(48.6)$ & $4(5.5)$ & $2(2.7)$ & $1(1.3)$ \\
\hline It is a part of self care & $12(16.6)$ & $32(44.4)$ & $16(22.2)$ & $10(13.8)$ & $2(2.7)$ \\
\hline Continue with self medication practice & $0(0)$ & $33(45.8)$ & $15(20.8)$ & $17(23.6)$ & $7(9.7)$ \\
\hline
\end{tabular}

1- strongly agree , 2- agree, 3 - unsure , 4- disagree , 5- strongly disagree.

Table 3: Perception of students to prevent self medication practice.

\begin{tabular}{|c|c|c|c|c|c|}
\hline $\begin{array}{l}\text { Perception of students to prevent self medication } \\
\text { practice }\end{array}$ & $\begin{array}{l}\mathbf{1} \\
\mathbf{N}(\%)\end{array}$ & $\begin{array}{l}2 \\
\mathbf{N}(\%)\end{array}$ & $\begin{array}{l}\mathbf{3} \\
\mathbf{N}(\%)\end{array}$ & $\begin{array}{l}\mathbf{N}(\%) \\
\end{array}$ & $\begin{array}{l}\mathbf{5} \\
\mathbf{N}(\%)\end{array}$ \\
\hline $\begin{array}{l}\text { Prevent dispensing of medicine without a valid } \\
\text { prescription }\end{array}$ & $33(45.8)$ & $14(19.4)$ & $14(19.4)$ & $6(8.3)$ & $5(6.9)$ \\
\hline $\begin{array}{l}\text { Creating awareness regarding side effects of self } \\
\text { medication }\end{array}$ & $41(56.9)$ & 23 (31.9) & 7 (9.7) & $0(0)$ & $1(1.3)$ \\
\hline $\begin{array}{l}\text { Making health care facilities affordable and } \\
\text { easily available }\end{array}$ & $41(56.9)$ & $19(26.3)$ & $10(13.8)$ & $0(0)$ & $2(2.7)$ \\
\hline
\end{tabular}

1- strongly agree , 2- agree, 3- unsure , 4- disagree , 5- strongly disagree. 


\section{DISCUSSION}

Analgesics have been the most commonly used and abused drugs for self medication. In present study, the prevalence of self medication with analgesics was found to be $83.3 \%$ while in studies done by Badiger et al, Shivamurthy et al, Al Essa et al, found prevalence of analgesic self medication to be $92 \%, 63.6 \%$ and $73.2 \%$ respectively., 4,9 Present study thus supports earlier studies with similar results signifying increasing self medication practice among medical students.

In present study, female students $(51.3 \%)$ practiced self medication more than male students $(48.6 \%)$ which differs from study conducted by Badiger $\mathrm{S}$ et al, where male students practiced self medication $(94 \%)$ more than female students $(91 \%)$.

In present study, majority of the students had some knowledge about the actual definition of self medication $(87.5 \%)$, difference between opioid and nonopioid analgesics $(90.2 \%)$, dose of analgesic used $(90.2 \%)$, duration of treatment $(91.6 \%)$, dosage forms $(94.4 \%)$, timing of administration (88.8\%), side effects $(90.2 \%)$, drug interactions (94.4\%), banned analgesics (58.3\%) which is comparable to a study done by Rani $\mathrm{N}$ et al, comparing self medication practice among MBBS and BDS students, which showed that $99 \%$ of the MBBS students were aware of self medication compared to $70 \%$ in dental students. ${ }^{10}$ Sufficient pharmacological knowledge enables Medical students to indulge in self medication practice.

In present study, self medication with analgesics was used for headache $(59.7 \%)$ and Nonsteroidal antiinflammatory drugs (NSAIDs) (90\%) were the commonly used drugs which is similar to studies done by Shivamurthy et al, Al Essa et al, where headache $(68.2 \%$ and $92 \%$ respectively) was the most common indication and NSAID paracetamol (47\%, 96.5\%) was most commonly used analgesic. ${ }^{8,9}$ This practice of self medication with analgesics for minor illness is common as they believed that no other medical intervention is required. This trend of analgesic self-use could mask the actual diagnosis of the underlying disease.

The most common reason for self medication in our study was quick relief $(73.3 \%)$ which is similar to study done by Gupta V et al, and prior experience of illness (38.3\%) reported in present study was also reported from studies done in Zafar et al and Abay et al. ${ }^{11-13}$ Time saving was the reason for self medication with analgesics in the study done by Shivamurthy $\mathrm{S}$ et al which is different from present study. ${ }^{8}$ In present study, most common source of drug information was from medical textbooks $(61.6 \%)$ which is similar to studies done by Badiger et al and Abay SM et this study was also reported by Shivamurthy et al. ${ }^{8}$ The participants thus indulged in self medication practice owing to their self-assumed sufficient pharmacological knowledge.
In present study, students normally stopped taking self medication with analgesics after the symptoms disappeared $(75 \%)$ while only $10 \%$ of them stopped the analgesics after consulting a doctor. In a study done by Al Essa et al, 53\% of the students visited the physician one to three times during the previous year to consult the doctor for medical illness. ${ }^{4}$ Medical Students not consulting the doctor might be they felt that they had sufficient knowledge to deal with minor illness.

In the present study, $44.4 \%$ of the participants think that self medication with analgesics is a part of self care while it was higher $91.97 \%$ in a study reported by Shivamurthy et al. ${ }^{8}$ In present study students agreed that Medical license is required for better administration of drugs $(51.3 \%)$.

\section{CONCLUSION}

This study has found that self medication with analgesics was common among undergraduate medical students for minor illness. This is facilitated by easy availability of drug information from medical textbooks. This trend of easy availability of over the counter analgesics can lead to drug tolerance, dependence (with opioids) and also mask the actual diagnosis of the underlying disease. Though the participants think that self medication is a part of self care the students strongly agreed that medical license is required for better administration of drugs. It is necessary to create awareness and educate students regarding dangers of analgesic self medication.

\section{ACKNOWLEDGEMENTS}

Authors are thankful to the students of $5^{\text {th }}$ term MBBS, Studying in Dr. B. R. Ambedkar Medical College, Bengaluru, who voluntarily participated in the questionnaire based study.

Funding: No funding sources

Conflict of interest: None declared

Ethical approval: The study was approved by Institutional Ethics Committee of Dr. B. R. Ambedkar Medical College, Bengaluru, Karnataka

\section{REFERENCES}

1. WHO (2000). Guidelines for the regulatory assessment of medicinal products for use in selfmedication. Geneva. Available at: http://apps.who. int/medicinedocs/pdf/s2218e.pdf. Accessed 10 December 2013.

2. Banerjee I, Bhadury T. Self-medication practice among undergraduate medical students in a tertiary care medical college, West Bengal. J Postgrad Med. 2012;58(2):127-31.

3. Sontakke SD, Bajait CS, Pimpalkhute SA, Jaiswal KM, Jaiswal SR. Comparative study of evaluation of self-medication practices in first and third year 
medical students. Int J Biol Med Res. 2011;2(2):5614.

4. Badiger S, Kundapur R, Jain A, Kumar A, Pattanshetty S, Thakolkaran N, et al. Self-medication patterns among medical students in South India. Australas Med J. 2012;5(4):217-20

5. Klemenc-Ketis Z, Hladnik Z, Kersnik J. Selfmedication among health care and non-healthcare students at University of Ljubljana Slovenia. Med Princ Pract. 2010;19(5):395-401.

6. Lukovic JA, Miletic V, Pekmezovic T, Trajkovic G, Ratkovic N, Aleksic D, et al. Self-medication practices and risk factors for self medication among medical students in Belgrade, Serbia. PloS One 2014;9(12):e114644.

7. Self-medication popular among medical students: AIIMS study. Available at: http://www.livemint. com/Politics/XcN44QD5g8aW4dwltcUdtI/Selfmedic ation-popular-among-medical-students-AIIMSstudy.html. Accessed 06 March 2015.

8. Shivamurthy S, Manchukonda R, Gurappanavar D. Evaluation of analgesic self-medication pattern among under-graduate medical students of Adichunchanagiri Institute of Medical Sciences, BG Nagar, Karnataka: a cross-sectional questionnairebased study. Int $\mathrm{J}$ Basic Clin Pharmacol. 2015;4(3):438-41.

9. Al-Essa M, Alshehri A, Alzahrani M, Bustami R, Adnan S, Alkeraidees A, et al. Practices, awareness and attitudes toward self-medication of analgesics among health sciences students in Riyadh, Saudi Arabia. Saudi Pharm J. 2019;27:235-9.

10. Rani N, Sadi S, Khajuria K. Comparative study of knowledge, attitude and practice of self medication among undergraduate students of MBBS and BDS. Int J Basic Clin Pharmacol. 2018;7(12):1-5.

11. Gupta V, Bansal P, Manhas R, Singh Z, Ghaiye P. Preferred system of medicine and reasons of selfmedication among college students in Malwa region of Punjab. J Drug Deliv Ther. 2011;1(2):27-9.

12. Zafar SN, Syed R, Waqar S, Irani FA, Saleem S. Prescription of medicines by medical students of Karachi, Pakistan: a cross-sectional study. BMC Public Health. 2008;8:162.

13. Abay SM, Amelo W. Assessment of self-medication practices among medical, pharmacy, and health science students in Gondar University, Ethiopia. J Young Pharm. 2010;2(3):306-10.

Cite this article as: Shanmukananda $\mathrm{P}$, Shwetha $\mathrm{H}$, Veena DR, Poorvi M. A cross sectional questionnaire based study on self medication practice of analgesics among MBBS students at Dr. B. R. Ambedkar Medical College, Bengaluru, Karnataka. Int J Basic Clin Pharmacol 2020;9:633-7. 